Original Research Paper

\title{
Ideology, Decision Planning and Operational Scenarios and Features in Cross Docking Models
}

\author{
${ }^{1}$ Wan Nor Ashikin Wan Ahmad Fatthi, ${ }^{2}$ Adibah Shuib, ${ }^{2}$ Rosma Mohd Dom, ${ }^{2}$ Ainon Mardhiyyah Shahidin \\ ${ }^{1}$ Department of Computer and Mathematical Sciences, Universiti Teknologi MARA (UiTM), Negeri Sembilan, Malaysia \\ ${ }^{2}$ Faculty of Computer and Mathematical Sciences, Universiti Teknologi MARA (UiTM), Selangor, Malaysia
}

Article history

Received: 24-02-2014

Revised: $13-04-2014$

Accepted: 02-01-2015

Corresponding Author: Wan Nor Ashikin Wan Ahmad Fatthi,

Department of Computer and Mathematical Sciences, UiTM, Negeri Sembilan, Malaysia E-mail: ashikin7463@ns.uitm.edu.my

\section{Introduction}

The competitive global market environment has increased the pressure on manufactures, retailers and distributors to rapidly supply products to end-customer. Managing cost becomes more and more important theme. Therefore companies attempt to eliminate activities that do not add value especially in the warehouse flow process. One of the new innovative strategies in warehousing which has recently been implemented is cross docking. Cross docking is a technique that offers short cycle time by allowing direct transhipment of products from the incoming to the outgoing truck without any storage or with just temporary storage in between (Acar, 2004; Chen et al., 2009). Usually shipments will spend less than $24 \mathrm{~h}$ or less that one hour in the facility before being shipped to the intended customers (Shuib and Fatthi, 2012).

In a cross docking model, customer is known before the goods get to the warehouse. When the freight arrives to the facility, they are directly sorted and sent to the assigned customer. Thus, the storage function has been eliminated. As there is no inventory in storage due to direct transhipment, cross docking has been a potential logistic technique in order to reduce the inventory holding cost, order picking cost, transportation cost and delivery time (Apte and Viswanathan, 2000). In fact, cross docking system has been successfully applied in many industries and several famous companies such as Wal-Mart, FedEx Freight, Toyota, Goodyear GB Ltd and Kodak Co (Boysen, 2010; Chen et al., 2009; Shakeri et al., 2008).

According to Goliasa et al. (2010), the problem related to cross docking facilities can be divided into two categories, which are, (a) problem that considers the facility as a node within a larger transportation network and (b) problem that focuses on the operations of the facility, which account for processes at inbound doors, staging areas and outbound door. In general, the problem that considers the facility as a node deals with the routing of vehicles from or to the cross dock facility such as described in Lee et al. (2006), location and demand allocation to the cross dock facility (Dobrusky, 2003) and design of the supply chain network problem (Bachlaus et al., 2008). For the latter problem, which focuses on the operations of the cross dock facility, there are two main issues, namely, the optimization of operations at inbound and outbound doors (Choi et al., 2006; Miao, 2006) and optimization of operations within the storage area of cross dock facility, as stated in (Goliasa et al., 2010; Yu and Egbelu, 2008). Hence, effective planning strategies are very crucial to ensure efficient operations at cross docking terminal.

This study focuses on short term planning of cross docking models. Operational issues and features 
addressed in the existing literature are discussed in detail. On top of that, the concept of cross docking and the planning decision levels are highlighted. This paper is organized as follows: An introduction of cross docking is presented first, followed with the description on traditional warehouse versus cross docking warehouse. The cross docking planning is highlighted next. Meanwhile, the operational issues and features addressed in the current cross docking model is discussed in detail. Hence, conclusion of this study is provided as well.

\section{Traditional Warehouse Versus Cross Docking Warehouse}

Before the existence of warehouse, commodities are sent from vendor to the customers in direct distribution so called as direct shipment. It is a normal case for customers (retail stores) who deal with many vendors just to have only one order for each vendor. Thus, usually the shipments are delivered by the vendor's truck in LessThan-Truckload (LTL). LTL refers to the transportation of relatively small freight that requires space or weight which is less than the truck capacity. This is not economical for both parties as a customer has to pay more for deliveries due shipments from many vendors while a vendor has to bear for high delivery cost because of the LTL. As a result, warehouse is initiated to serve as an intermediate point between vendors and customers.

To be more specific, a warehouse is a commercial four wall building which is used by manufacturers, importers, exporters, wholesalers, logistics providers, for storage and handling of goods (Emmett, 2011; Ling, 2007). Warehouse usually consists of separate unloading and loading docks to unload and load the goods. Two primary functions of a warehouse include (i) temporary storage and protection of goods; and (ii) providing value added services such as fulfilment of individual customer orders, packing of goods, after sales services, repairs, testing, inspection and assembly (Heragu et al., 2004). Based on (Rouwenhorst et al., 2000; Gu et al., 2007), operations in a warehouse can be summarized as in Fig. 1.

Cross docking is a logistics technique that eliminates the storage and order picking function of a warehouse while still allowing the warehouse to serve its receiving and shipping functions (Bartholdi and Gue, 2004). The primary purpose of a cross dock is to enable a consolidation from many smaller shipments between multiple shippers and recipients, so that only full truck loads are transported. Using this way, economies of transportation are realized (Apte and Viswanathan, 2000). Instead of shipping small orders directly as LTL shipments between origins and destinations, cross docking consolidates small orders into Truck-Load (TL) shipments (Yang et al., 2010). Figure 2 shows the process involved in the traditional warehouse and cross docking warehouse.

Van Belle et al. (2012) listed some advantages of cross docking as compared to traditional warehouse, which are:

- Cost reduction (warehousing costs, inventory holding cost, handling costs)

- Shorter delivery time (from supplier to customer)

- Reduction of storage space

- Faster inventory turnover

- Fewer overstocks

- Reduced risks for loss and damage
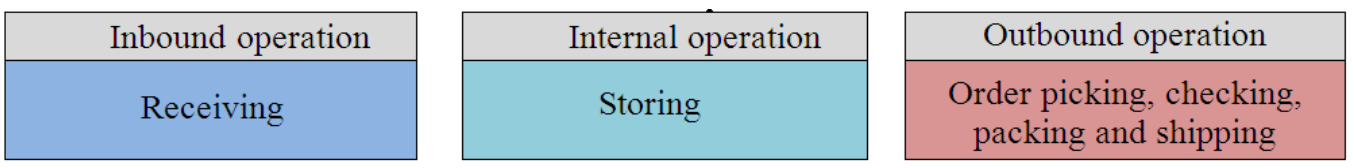

Fig. 1. Warehouse operations

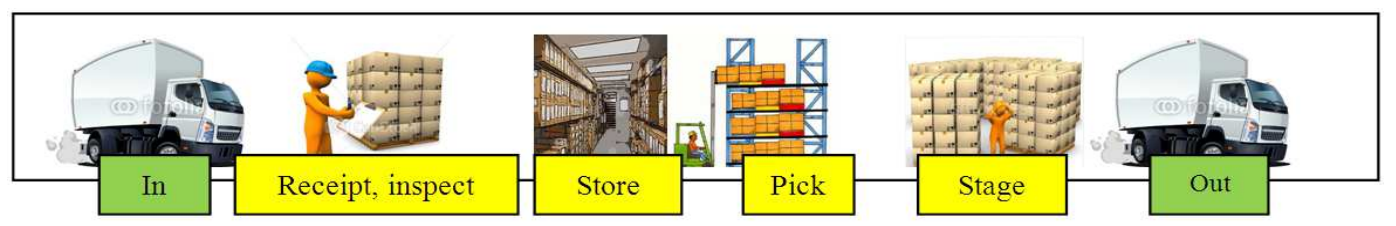

Goods flow through traditional warehouse

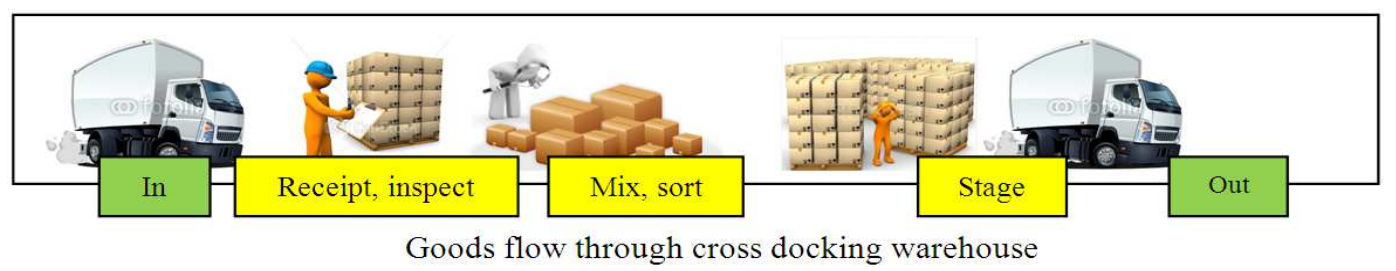

Fig. 2. Traditional warehouse versus cross docking warehouse 
According to Napolitano et al. (2000), the term 'cross docking' can be classified based on different types of functions as the following:

- Manufacturing cross docking-receiving and consolidating inbound supplies to support Just-InTime manufacturing

- Distributor cross docking-consolidating inbound products from different vendors into a multi-SKU pallet, which is delivered as soon as the last product is received

- Transportation cross docking-consolidating shipments from different shippers in the Less-Than-Truckload (LTL) and small package industries to gain economics of scale. For small package carriers, material movement in the cross dock is by a network of conveyers and sorters; for LTL carriers it is mostly by manual handling and forklifts

- Retail cross docking-receiving product from multiple vendors and sorting onto outbound trucks for different stores

- Opportunistic cross docking-in any warehouse, transferring an item directly from receiving dock to the shipping dock to meet a known demand

Cross docking practise was pioneered by the WalMart Corporation where about $85 \%$ of its commodities are delivered through cross dock facilities (Saxena, 2007). Because Wal-Mart was able to reduce the total system inventory with cross docking, it could offer the "everyday low price" (Stalk et al., 1992). A survey carried out by Saddle Creek on 547 industry professionals showed that $68.5 \%$ of the respondents have already used cross dock and $15.51 \%$ plan to do so within the next one to two years (Creek, 2011). For examples, many famous companies such as Home Depot, Costco, Canadian Tyre, FedEx Freight, Kodak Co, Goodyear GB Ltd, Toyota, are now implementing cross docking system (Chen et al., 2009).

\section{Cross Docking Planning}

Models of cross docking planning can be divided into three decision levels, which are strategic, tactical and operational level. For strategic level, the decision made is usually associated for the long time horizon and addresses the problem of cross docking network design such as determination of number of cross docking warehouses, location of the facility and number of vehicles in the network. Several works on cross docking strategic planning can be found in (Kreng and Chen, 2008; Bachlaus et al., 2008). On the other hand, in the tactical decision level of cross docking planning, the planning horizon of the decision is the mid-term horizon. Studies in tactical level mainly discussed the problem of cross docking layout design (Bartholdi and Gue, 2004; Heragu et al., 2004; Vis and Roodbergen, 2008). A good layout will significantly affect the effectiveness and the efficiency of the operations inside the cross docking warehouse. Besides, some works in the cross docking layout design are related with the dock door assignment problem.

In order to operate and manage the cross docking facility in a more systematic way and economically, planning at operational decision level is also required. This planning commonly deals with the short-term planning horizon such as daily or weekly. Studies under cross docking operational planning can be divided into five major problem areas which are scheduling problem (Arabani et al., 2012; Boysen, 2010; Mentzer et al., 2011), dock door assignment problem (Aickelin and Adewunmi, 2008; Berghman et al., 2011), transhipment problem (Larbi et al., 2009; Miao et al., 2010), vehicle routing problem (Dondo et al., 2011) and product allocation problem such as in Li et al. (2008). An overall cross docking planning and decision levels can be summarized as in Fig. 3.

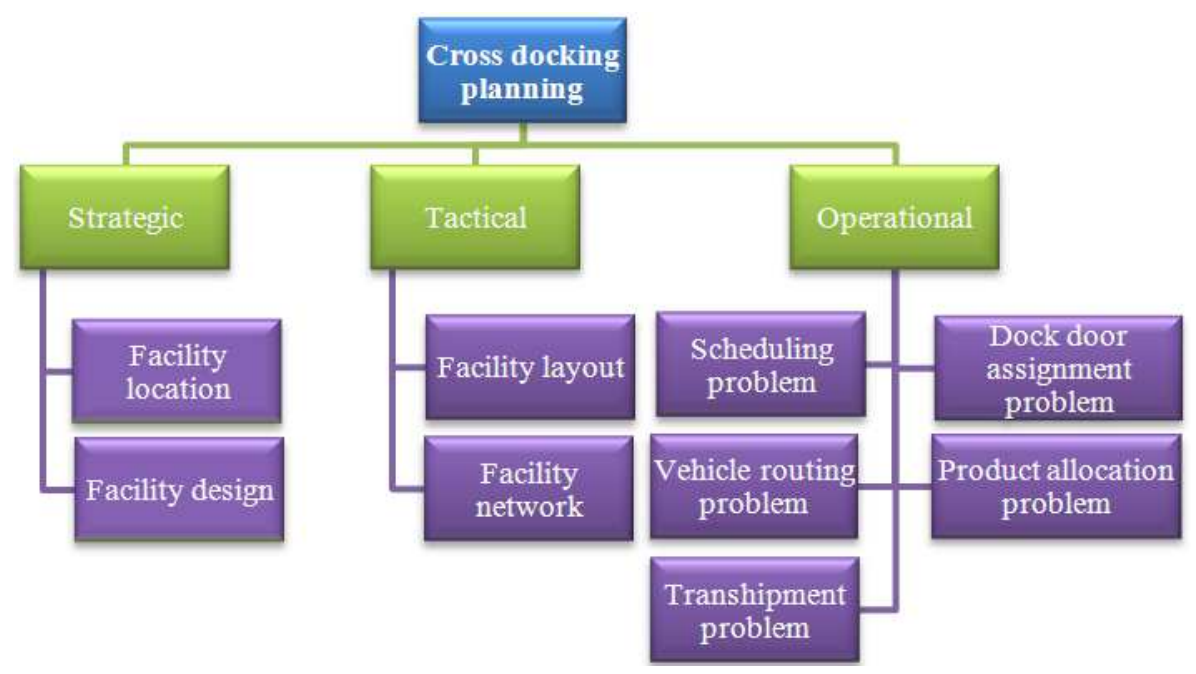

Fig. 3. Decision levels in cross docking planning 


\section{Operational Scenario and Features in Cross Docking Models}

A specific modelling approach may be required to address the planning and operations at each of the phases of the cross docking operations, namely the inbound, internal and the outbound operation. The modelling approach may depend on the type of the cross docking centre (retail, manufacturing, distributor, transportation or opportunistic) as well as the distinctive scenarios and features encountered at the three phases of its operations such as the setting and facility layout, products and packaging, equipment and labours or whether the planning addressed static or dynamic operations. These scenarios and features dictate the planning and operational strategies that need to be adopted by the cross docking management. In this study, example of 32 existing short term cross docking models have been studied carefully. Scenario and strategies addressed for each model is identified and the result is shown in Table 1.

Problems that characterize the inbound operation are the door assignment and truck scheduling problem, which are normally considered as short term problems in cross docking planning. The door assignment and scheduling problem concerns with coordinating the services provided at dock doors where each door might serve multiple suppliers' trucks or destination stores per day whereas the service time for the truck at each door varies according to the capacity and products' types and packaging. If dynamic arrivals of trucks is not considered, the door assignment decision can also be determined based on mid-term horizon planning, where each dock door has been pre-determined to serve certain inbound trucks or outbound destinations for some period of time such as a week or a month. For example, Bozer and Carlo (2008) addressed two types of door assignment namely, the static and dynamic assignment. In static door assignment, the assignment destination of outbound door is determined to be fixed over a planning horizon (such as 3 to 6 months) while the inbound doors are assigned nightly.

Although a fixed assignment of doors to destinations will simplify the allocation of shipments to trucks, it may restrict the practicality in short term scheduling because the peak loads for single destination cannot be accommodated with additional dock doors or trucks. Thus, such fixed door assignment seems suited and applicable only for steady commodity flows with a reliable distribution among inbound and outbound destinations (Boysen and Fliedner, 2010). The list of previous studies concerning static and dynamic strategies of dock door assignment and scheduling is given in Table 1.

A common scenario of truck scheduling of inbound operation considered in the existing studies is the assumption of static trucks' arrivals. With the aim of reducing the complexity in the modelling approach, most of the research on cross docking planning outlined an assumption for all trucks to be available at time zero or the arrival sequences is assumed to be known. In this scenario, trucks are assumed to be already waiting on the designated area and are ready to be called up for unloading when the schedule starts. However, in the real world situation of cross docking implementation, supplier's trucks arrive dynamically over time, before and after the starts of schedule. Thus, a possibility for a number of trucks to arrive at the same time during peak hours is high and this might result in trucks congestion and long waiting time in queues due to inappropriate scheduling policy and strategies. However, truck-to-door assignment and scheduling with dynamic arrival time of trucks is a complex problem and has been proven to be an NP-hard problem (Sadykov, 2012). NP-hard problems are referred to the optimization problems which have no solution in polynomial time.

Most cross docks doors are categorized into unload and load positions known as unloading and loading doors, receiving and shipping doors or strip and stack doors. These doors provide the space required by the trucks for unloading or loading. The classic and most popular layout of a cross docking facility is rectangular in shape with several tens of load or unload doors on each of the longer sides of the rectangle (Cohen and Keren, 2008). In other words, one side of the cross docking facility is for inbound operation while the other side for outbound operation (Tsui and Chang, 1992). According to Boysen and Fieldner's (2010) classification, this split doors environment is recognized as an exclusive mode of service door. An exclusive mode service with split doors is shown in Fig. 4.

Nevertheless, due to technical restriction for a separation of inbound and outbound trucks, there are also facilities which offers mixed service mode where the doors of a cross dock can have dual functions of inbound and outbound at the same time and trucks just exchange some of their products with each other at these doors. Cross docking in this scenario can be described as the following. A number of supplier/customer trucks are docked in the cross dock yard, exchange their products based on the demands from predefined customers and leave the cross docking terminal as an outgoing trucks. The second row of Table 1 presents the existing studies which concerned with exclusive mode and mixed mode of cross docking doors configuration, respectively.

For the truck scheduling problem in cross docking facility, unavailability of dock doors, material handling equipment, workers and also insufficient space for intermediate storage will cause delays and affect the total operation time. In fact, these limited resource constraints commonly result in prolonged completion time of jobs. Door unavailability occurs when the number of trucks in the cross docking waiting area exceeds the number of available dock doors, resulting in some waiting time for the truck. In real practice of cross docking, the number of 
incoming trucks during peak hours is always greater than the number of available docks doors. However, some studies assumed that the number of incoming trucks does not go beyond the number of doors at any time. This assumption might be applicable only for the large LTL cross docking with hundreds of doors and the queue of trucks rarely exceeds the number of doors or the size of queue is just few (Gue, 1999). For the case when the number of trucks is greater than the dock doors, an effective truck assignment and scheduling procedure is crucial in order to smoothen the flow of trucks and freights and saving the operations costs.

Once the freights unloaded from trucks, they will be handled by some material handling equipment such as forklift and pallet jack, as shown in Fig. 5. In cross docking, the service time of a truck may be affected by the number of material handling equipment available to unload, move or load the products (Goliasa et al., 2010). Some studies assumed that the number of this material handling equipment is sufficient. Thus, with this assumption, the truck's service time will not be affected by resource constraints associated with the material handling equipment. The third row of Table 1 presents the previous works which addressed the operational resource constraints in cross docking.

According to Goliasa et al. (2010), shipments arriving at the cross dock facility may be loaded directly on an outbound truck (one-touch complexity); staged on the dock and then loaded onto an outbound truck (twotouch complexity); or staged on the dock, reconfigured and then loaded on an outbound truck (multiple-touch complexity). In two-touch complexity, usually the shipments need to be temporarily staged onto an intermediate storage inside the cross dock due to the number of shipping trucks exceeds the number of outbound doors. The intermediate storage area; also known as staging area, is normally located in front of the shipping doors where the products have to be staged before being loaded to the outbound truck. On the other hand, the applicability of intermediate storage area is dependent on the type of cross docking centre itself that determines whether there will be no intermediate storage area, limited intermediate storage area or unlimited intermediate storage area. For example, Boysen (2010) considered a cross docking operation for food industry where strict cooling requirement forbid an intermediate storage inside the facility such that all shipments must be transferred directly to the outbound trucks instantaneously. Thus, the cross docking operation is conducted by holding no-wait property as classified by (Boysen and Fliedner, 2010). Some of the existing studies pertaining to the intermediate storage area are also presented in Table 1 .

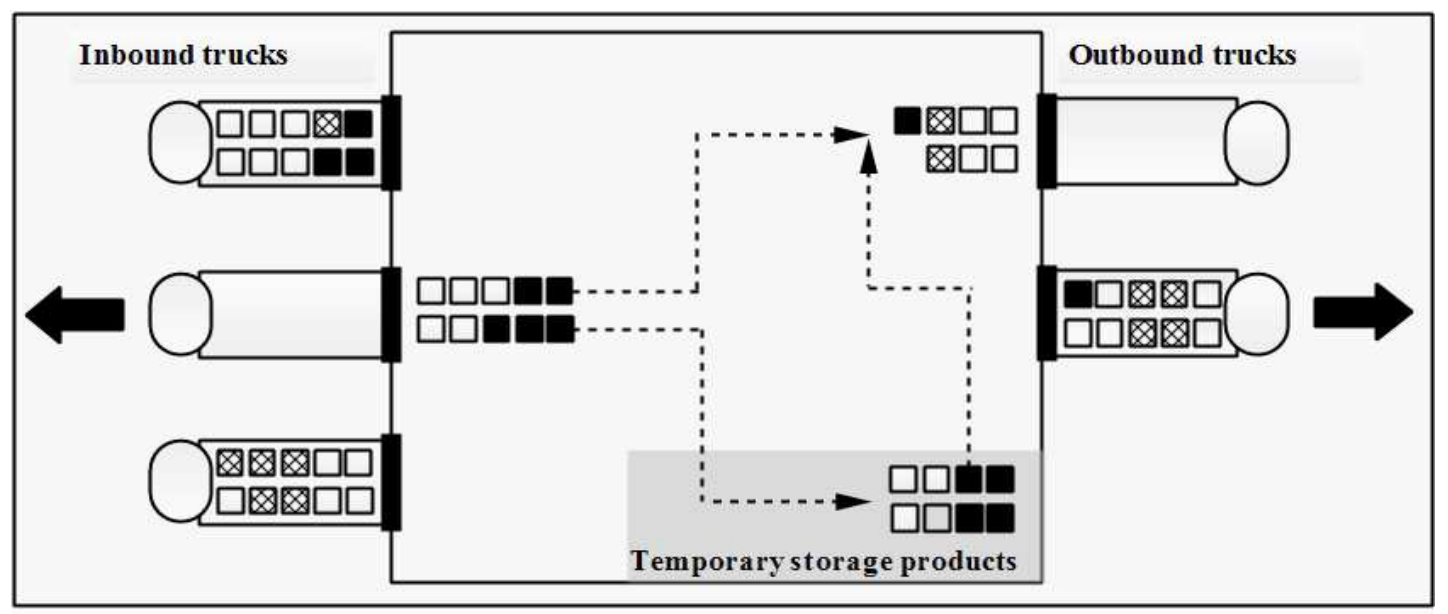

Fig. 4. Exclusive mode service with split doors
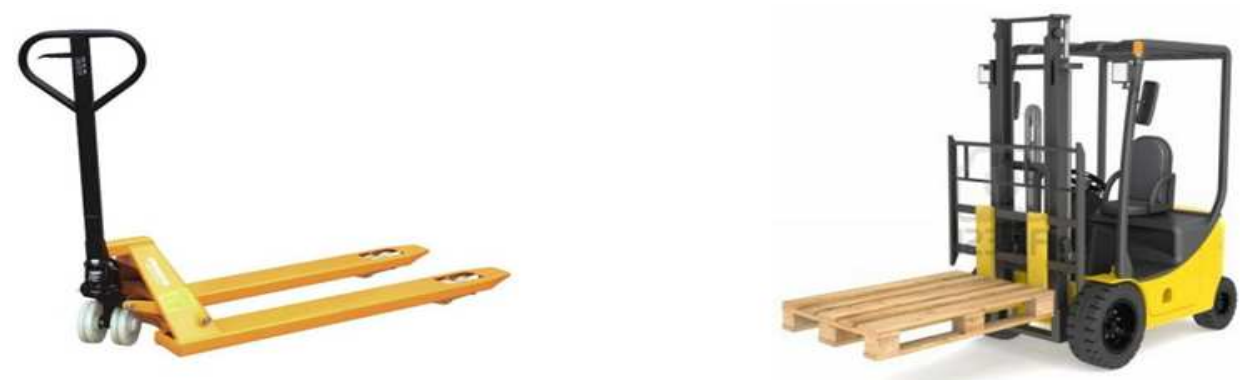

Fig. 5. Pallet jack and forklift used for material handling 
Wan Nor Ashikin Wan Ahmad Fatthi et al. / American Journal of Applied Sciences 2014, 11 (12): 2004.2015

DOI: $10.3844 /$ ajassp.2014.2004.2015

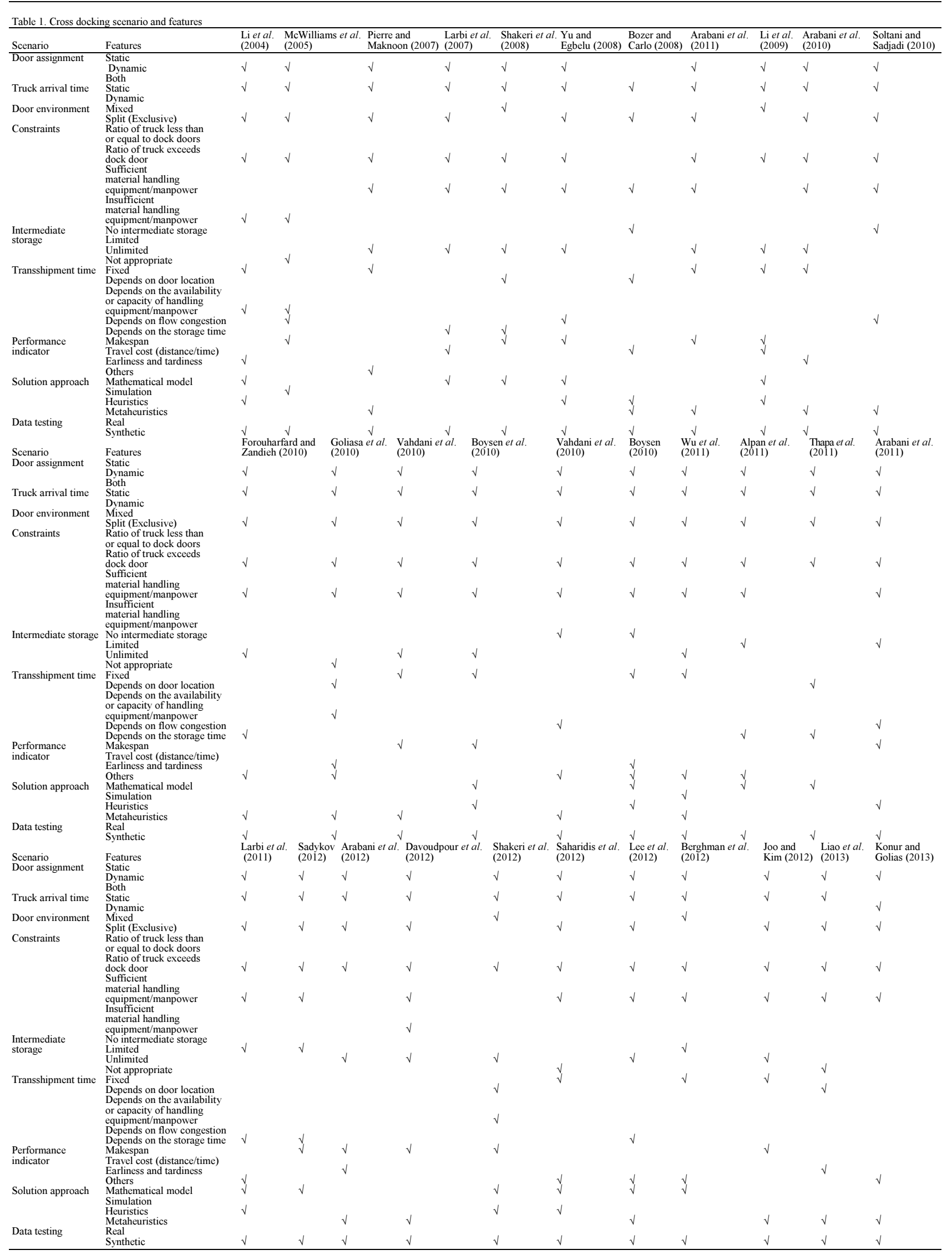


One of the factors which contribute to complexity in truck scheduling is the transhipment time in the cross docking facility. Boysen and Fliedner (2010) define the transhipment time as the time lag between the arrivals of shipments inside the facility after having unloaded them from their respective inbound truck until their availability at an outbound door. Transhipment time depends on several factors such as the location of door, availability of forklift or manpower and also congestion flow of products inside the cross dock. The location of doors also represents the distance to be covered by material handling equipment where it may take more transhipment time to move the products from inbound door to far outbound door rather than the adjacent one. Sometimes, due to the large freight to be handled, limited numbers of forklifts will create delay in transhipment of products because the forklifts may have to do more than one trips for moving the items. Cross dock congestion, which caused by the forklifts and products, can also result in long transhipment time as well. Specifically, interference due to forklifts, dragline congestion and congested floor space (Bartholdi and Gue, 2000), will increase the time for moving the products between two doors. Meanwhile, time incurred at the intermediate storage area will also contribute to the total time of transhipment. Thus, in order to reduce the complexity of the problem, some studies assumed the transhipment time to be constant or fixed. However, such assumption might be practical if the cross docking facility only has few doors, unlimited temporary storage area and sufficient forklift for handling the shipments. Some existing studies on transhipment time strategies of cross docking operation are as listed in Table 1.

The productivity of cross docking is heavily dependence on the performance of overall operations at the cross docking centre. One of the common performance indicators used for evaluating the cross docking operation is the total operation time or the length of schedule (schedule length) starting from the first product from first scheduled truck is unloaded until the last product of last scheduled truck is loaded. In the traditional machine scheduling problem, the schedule length is also known as makespan. Mostly, makespan is focusing on the time when the last shipment is finally loaded. Many studies such as by (Shakeri et al., 2008; Boysen et al., 2010; Arabani et al., 2011; Sadykov, 2012) put forward minimizing makespan as the objective of their optimization models. Besides makespan, the travel cost or specifically, the travel distance, also received attention in measuring the cross docking operation, see Aickelin and Adewunmi (2008). In cross docking studies by (Larbi et al., 2007; Bozer and Carlo, 2008; Li et al., 2009) for examples, the objective of the model is to minimize the total travel distance of transferring freight from the inbound door to the outbound door. Travel distance affects the travelling time of products since the time taken for moving the products inside the cross dock generally depends on the relative distance between the dock door to which the respective inbound and outbound truck have been assigned. Assigning an outbound door to be closest to the inbound door at which the products to be shipped are being unloaded is perceived to be able to reduce the travel distance thus, time required for moving the products. However, factors such as unavailability of forklift, shortage of workers and dock door congestion might lengthen the travelling time even though the distance from door to door has been made the shortest one.

In some cases of cross docking, customers already specified the expected arrival time of the products ordered, which is also called as due date. Thus, the respective dispatcher (cross docking operation manager) has to be alert about this to avoid tardiness on shipping the final products. If the vendor trucks arrive to the cross dock beyond the expected time, the process of mixing, matching and consolidating the whole products will be delayed. Consequently, the final product is unable to be shipped on time. Thus, with the interest in Just In Time (JIT) scheduling, the performance of cross docking can also be measured based on the truck's earliness and tardiness that considers predefined arrival and departure of the trucks. Examples of studies which concerns about the tardiness of the outbound trucks are represented by (Li et al., 2004; Arabani et al., 2010; Boysen, 2010; Liao et al., 2013). Depending on the requirement and type of the cross docking itself, the operation performance can be measured by using different objectives such as to minimize the total storage cost of commodity, to maximize flow of transhipment or to minimize number of workers in the terminal. These criteria are denoted as other strategies in the Table 1.

To solve the cross docking problem, many approaches have been employed. The solution approaches viewed is not just from the quantitative aspect but also from qualitative perspective. For quantitative approaches, mathematical models such as linear programming, integer programming, multi objective programming, dynamic programming and statistical models have been developed. The mathematical programming models deals with maximization and/or minimization of certain objective function(s) whether in the form of single objective or multi-objectives (Goliasa et al., 2010; Larbi et al., 2011; McWilliams et al., 2005; Soltani and Sadjadi, 2010). Aside from that, simulation technique is also used to simulate the performance of the cross docking centre in a controlled environment in order to estimate what the actual performance will be Aickelin and Adewunmi (2008). In addition, heuristic and meta heuristics techniques have been proposed in order to solve the large scale instances problem of cross docking operation (Larbi et al., 2011; Shakeri et al., 2012; Wu et al., 2011). 
When there is no real data to justify the proposed solution model, synthetic data are generated to meet specific needs and certain conditions. Somehow, some justifications are required to validate that the synthetic test data is reliable to represent the real one. For instance, Soltani and Sadjadi (2010; Wu et al., 2011; Lee et al., 2012) generate the synthetic data in solving the large scale test problems in order to prove their proposed models. The list of papers concerning various types of data used is shown in Table 1.

\section{Results}

There are 32 existing cross docking models reviewed in this study. Models studied are concerning on the short-term scheduling planning at the cross docking facility. There are nine common scenarios addressed by the existing short term scheduling models. The scenarios are the door assignment, truck arrival time, door environment, constraints, intermediate storage, transshipment time, performance indicator, solution approach and data testing.

Commonly, there are two features of the door assignment specified by the cross docking warehouse which are static, dynamic or static and dynamic. As cross docking aims on minimizing the cost and maximizing the throughput, dynamic door assignment has always been the focus by existing studies. This is proved by 31 models studied as shown in Table 1. In dynamic door assignment, the inbound and outbound doors are not restricted to receive shipments for only single destination. On the other hand, a study conducted by Bozer and Carlo (2008), have addressed the scheduling problem in which the inbound door of the cross docking facility have dynamic assignment decision and is optimized on a nightly basis, whereas, the outbound doors have fixed assignment decision for specific period of time (such as 60 days).

Aside from that, the gap analysis conducted shows that most of cross docking scheduling models assumed static arrival time of the incoming truck, either the trucks are assumed to be available before the start of schedule or the arrival time of trucks are known beforehand. For instance, the model proposed by (Shakeri et al., 2008; Forouharfard and Zandieh, 2010; Joo and Kim, 2012) have specified that all trucks are assumed to be available at the cross docking facility at time zero. A study conducted by Konur and Golias (2013) is the only recent work that has addressed the dynamic arrival time of trucks. Although the authors attempt to present the realistic nature of cross docking operations by accounting for the uncertainties of truck arrival, but the specific time window for the incoming truck is known in advance.

Certain cross docking warehouses offer the mixed door environment where the inbound doors are also allowed to be functioned as the outbound doors. In mixed door environment, two situations are commonly occurred. First, the incoming trucks will load the freight carried to the inbound door and will receive their ordered freight later at the same door after finish loaded or two trucks are allowed to docked at the same door for two different tasks (loading or receiving). Studies carried out by (Shakeri et al., 2008; 2012; Li et al., 2009; Berghman et al., 2012) are the example of works that have addressed the feature of mixed door environment. On the other hand, split or separate door environment is considered for the cross docking layout in order to avoid technical interference and ease the truck's coordination (Pierre and Maknoon, 2007; Soltani and Sadjadi, 2010; Goliasa et al., 2010; Wu et al., 2011).

Delays in the cross docking scheduling are often caused by the constraints of resources such as number of receiving doors, insufficient handling equipment or lack of manpower. High number of incoming trucks at the facility as compared to the receiving doors has always been the reality for the cross docking application. As a result, 31 models studies as shown in Table 1 have put forward this issue as the constraint for modelling the cross docking problem. Meanwhile, studies carried out by (Li et al., 2004; McWilliams et al., 2005; Davoudpour et al., 2012) have highlighted the issue of insufficient material handling equipment and manpower as the factors that could lengthy the schedule.

Sometimes, received products cannot be directly loaded to the outbound trucks but must be temporarily staged inside the terminal for some specific of time (less than $24 \mathrm{~h}$ ). The intermediate storage or also refers to staging area could be limited or unlimited as shown in the fifth row of Table 1, depending on the setting of cross docking warehouse and the type of products handled. However, there exists the cross docking warehouse in which there is no necessity for the intermediate storage in the operation as proposed by (Bozer and Carlo, 2008; Soltani and Sadjadi, 2010; Vahdani et al., 2010; Boysen, 2010).

In cross docking, transshipment time is commonly affected by the internal operation. There are several features of transshipment time addressed by the existing models namely the transshipment time that affected by door location, transshipment time that affected by availability (or capacity) of handling equipment and manpower, transshipment time that affected by freight's flow congestion and the transshipment time that affected by the storage time. However, in order to simplify the model proposed, few studies such as in (Baptise et al., 2007; Saharidis et al., 2012; Joo and Kim, 2012) have assumed that the transshipment time is fixed.

Cross docking optimization will be guided by some objectives or performance indicators, which evaluate the solutions. The completion time of cross docking operation or also known as makespan are among the indicators addressed by the existing studies. For instance, overall 14 existing work as shown in Table 1 have evaluate their proposed model by putting forward the minimization of 
completion time as the performance indicator. Aside from that, studies conducted by (Larbi et al., 2007; Bozer et al., 2008; Li et al., 2009) have focusing on the internal operation as the objective. In their studies, the aim is on minimizing the total cost of transshipment operations. In addition, total of six existing models as indicate in Table 1 have underlined the minimization of truck's earliness and tardiness as the objective to be achieved.

There are several methods considered by the existing studies for solving the proposed model. The methods are mathematical programming, simulation approach, heuristics and metaheuristics. Most of the works in cross docking short term problem have modeled their problem by using mathematical approach and hence, solve the proposed model by using heuristics and metaheuristics for finding the optimal solution ( $\mathrm{Li}$ et al., 2004; Yu and Egbelu, 2008; Li et al., 2009; Larbi et al., 2011; Lee et al., 2012). Aside from that, in order to prove the applicability of the proposed model, synthetic data are generated and used for the model testing. However, it is identified that none of the model proposed in the existing studies have utilized the real data for the model testing.

\section{Conclusion and Research Opportunities}

The gap analysis on the existing cross docking models pertaining to scenario and strategies shows that studies which concerns with dynamic arrival time of trucks is still lacking. This is due to the complexities to solve the scheduling problem under real-time modelling environment. Therefore, most works on cross docking planning models assume the truck to be present at time zero or the arrival sequence is assumed to be known. However, in real world situation of cross docking, supplier trucks arrived to the facility dynamically over time of facility operation's hour. Thus, deterministic scheduling with static environment may not be able to cater efficiently the arrival of trucks in dynamic environment and thus, dock doors congestion, long waiting hours in queues are bound to be encountered by the trucks.

On the other hand, it can be concluded that there are only few work considers the congestion issue inside the cross docking terminal itself. As the size of freight become larger in the terminal, more goods need to be handled and the handling process will require a faster manoeuvre of forklifts. Consequently, the usages of forklift will be multiplied and speedy movement is required and this may create congestion within the terminal. Hence, it will be a valuable contribution to investigate a more efficient assignment procedure for conducting this kind of material handling equipment. Meanwhile, focus should also be given for product assignment decision in order to ease the flow of products transhipment inside the facility. Delay in this internal operation will affect the outbound truck to leave facility on time. Thus, risk the freight to arrive to the intended customer beyond the schedule.

Aside from that, the analysis indicates that none of the existing studies verified their proposed model by using a real data. Instead, they used synthetic data. As cross docking operation is a daily day operation, comparing the computation result by using the proposed models with real data from cross docking facility will be a promising finding. Hence, promotes the proposed model as a convincing approach to be applied in the real world cross docking operation especially for distribution centre, manufacturers and logistics service providers.

Another important scenario which has been neglected in the current literature is the truck's unloading time. In reality of cross docking implementation, the truck-todoor assignment is carried out by randomly assigning truck to dock door. Sometimes, it is based on an operation staff intuition as to which door is appropriate by looking at the size of the truck and experience on unloading time for such truck or truck of certain supplier. Thus, the truck unloading time has never been used as a criteria in determining truck-to-door assignment. In addition, no tool has been developed thus far to systematically assess the truck unloading time despite the fact that knowledge on the unloading time is a valuable information which can be used to efficiently assign truck to dock door especially during busy hours. Some strategies on the unloading time's estimation which can be considered when modelling the non-automated cross docking problem are the features of products carried (i.e., pallet or loose cartoon), type of products, number of boxes or the weight of products carried per truck.

\section{Acknowledgement}

This study is funded by Research Management Institute (RMI), Universiti Teknologi MARA (UiTM) Malaysia, under grant number 600-RMI/DANA 5/3/RIF.

\section{Author's Contributions}

All authors equally contributed in this work.

\section{Ethics}

This article is original and contains unpublished material. The corresponding author confirms that all of the other authors have read and approved the manuscript and no ethical issues involved.

\section{References}

Acar, M.K., 2004. Robust dock assignments at less-thantruckload terminals. University of South Florida. 
Aickelin, U. and A. Adewunmi, 2008. Simulation optimization of the crossdock door assignment problem. Proceedings of Research Society Simulation Workshop, (SSW' 06), Leamington Spa, UK, pp: 1-3.

Alpan, G., L. Rim and P. Bernard, 2011. A bounded dynamic programming approach to schedule operations in a cross docking platform. Comput. Ind. Eng., 60: 385-396. DOI: 10.1016/j.cie.2010.08.012

Apte, U.M. and S. Viswanathan, 2000. Effective cross docking for improving distribution efficiencies. Int. J. Logistics Res. Applic., 3: 291-302. DOI: $10.1080 / 713682769$

Arabani, A.B., M. Zandieh and S.M.T.F. Ghomi, 2012. A cross-docking scheduling problem with subpopulation multi-objective algorithms. Int. J. Adv. Manufacturing Technol., 58: 741-761.

DOI: $10.1007 / \mathrm{s} 00170-011-3402-7$

Arabani, A.R.B., S.M.T. Fatemi Ghomi and M. Zandieh, 2011. Meta-heuristics implementation for scheduling of trucks in a cross-docking system with temporary storage. Expert Syst. Applic., 38: 19641979. DOI: $10.1016 /$ j.eswa.2010.07.130

Arabani, A.R.B., S.M.T.F. Ghomi and M. Zandieh, 2010. A multi-criteria cross-docking scheduling with just-in-time approach. Int. J. Adv. Manufacturing Technol., 49: 741-756. DOI: $10.1007 / \mathrm{s} 00170-009-2429-5$

Bachlaus, M., P.K. Mayank, C. Mahajan, R. Shankar and M.K. Tiwari, 2008. Designing an integrated multiechelon agile supply chain network: A hybrid taguchi-particle swarm optimization approach. J. Intelligent Manufacturing, 19: 747-761.

DOI: $10.1007 / \mathrm{s} 10845-008-0125-1$

Bartholdi, J.J. and K.R. Gue, 2000. Reducing labor costs in an LTL cross docking terminal. Operations Res., 48: 823-832. DOI: $10.1287 /$ opre.48.6.823.12397

Bartholdi, J.J. and K.R. Gue, 2004. The best shape for a crossdock. Trans. Sci., 38: 235-244.

DOI: $10.1287 /$ trsc. 1030.0077

Berghman, L., C. Briand, R. Leus and P. Lopez, 2012. The truck scheduling problem at cross-docking terminals. Proceedings of the 13th International Conference on Project Management and Scheduling, (PMS' 12), Louvain, Belgium, pp: 1-5.

Berghman, L., R. Leus and F.C.R. Spieksma, 2011. Optimal solutions for a dock assignment problem with trailer transportation. Ann. Operations Res., 213: 3-25. DOI: 10.1007/s10479-011-0971-7

Boysen, N. and M. Fliedner, 2010. Cross dock scheduling: Classification, literature review and research agenda. Omega, 38: 413-422.

DOI: $10.1016 /$ j.omega.2009.10.008

Boysen, N., 2010. Truck scheduling at zero-inventory cross docking terminals. Comput. Operations Res., 37: 32-41. DOI: 10.1016/j.cor.2009.03.010
Boysen, N., M. Fliedner and A. Scholl, 2010. Scheduling inbound and outbound trucks at cross docking terminals. Spectrum, 32: 135-161. DOI: $10.1007 / \mathrm{s} 00291-008-0139-2$

Bozer, Y.A. and H.J. Carlo, 2008. Optimizing inbound and outbound door assignments in less-thantruckload crossdocks. IIE Trans., 40: 1007-1018. DOI: $10.1080 / 07408170802167688$

Chen, R., B. Fan and G. Tang, 2009. Scheduling problems in cross docking. Combinatorial Optimization Applic., 5573: 421-429.

DOI: 10.1007/978-3-642-02026-1_40

Choi, E.J., H.J. Lee, C.S. Ko and B.N. Kim, 2006. A study on the dock door assignment problems in cross-docking terminal. Proceedings of the 7th Asia Pacific Industrial Engineering and Management Systems Conference, (API' 06).

Cohen, Y. and B. Keren, 2008. A simple heuristic for assigning doors to trailers in cross-docks. Proceedings of the International Conference on Industrial Logistics (ICIL' 08), pp: 1-14.

Creek, S., 2011. Cross docking trends report. Supply Chain Management Rev.

Davoudpour, H., P. Hooshangi-Tabrizi and P. Hoseinpour, 2012. A genetic algorithm for truck scheduling in cross docking systems. J. Am. Sci., 8: 96-99.

Dobrusky, F.G., 2003. Optimal location of cross-docking centers for a distribution network in Argentina. Massachusetts Institute of Technology.

Dondo, R., C.A. Méndez and J. Cerdá, 2011. The multiechelon vehicle routing problem with cross docking in supply chain management. Comput. Chemical Eng., 35: 3002-3024. DOI: $10.1016 /$ j.compchemeng. 2011.03 .028

Emmett, S., 2011. Excellence in Warehouse Management: How to Minimise Costs and Maximise Value. 1st Edn., John Wiley and Sons, Chichester, West Sussex, ISBN10: $1119995167, \mathrm{pp}: 314$.

Forouharfard, S. and M. Zandieh, 2010. An imperialist competitive algorithm to schedule of receiving and shipping trucks in cross-docking systems. Int. J. Adv. Manufacturing Technol., 51: 1179-1193. DOI: 10.1007/s00170-010-2676-5

Goliasa, M.M., S. Ivey, K. Ji and M.E. Lipinski, 2010. A bi-objective model to minimize service and storage time at a cross dock facility. Ann. Trans. Res. Forum.

Gu, J., M. Goetschalckx and L.F. McGinnis, 2007. Research on warehouse operation: A comprehensive review. Eur. J. Operational Res., 177: 1-21. DOI: 10.1016/j.ejor.2006.02.025

Gue, K.R., 1999. The effects of trailer scheduling on the layout of freight terminals. Trans. Sci., 33: 419-428. DOI: $10.1287 /$ trsc.33.4.419

Heragu, S.S., J.C.S. Huang, R.J. Mantel and P.C. Schuur, 2004. An efficient model for allocating products and designing a warehouse. Progress Material Handling Res. 
Joo, C.M. and B.S. Kim, 2012. Scheduling compound trucks in multi-door cross-docking terminals. Int. J. Adv. Manufacturing Technol., 64: 977-988.

DOI: $10.1007 / \mathrm{s} 00170-012-4035-1$

Konur, D. and M.M. Golias, 2013. Cost-stable truck scheduling at a cross-dock facility with unknown truck arrivals: A meta-heuristic approach. Trans. Res. Part E: Logistics Trans. Rev., 49: 71-91. DOI: $10.1016 /$ j.tre.2012.06.007

Kreng, V.B. and F.T. Chen, 2008. The benefits of a cross-docking delivery strategy: A supply chain collaboration approach. Production Planning Control, 19: 229-241. DOI: $10.1080 / 09537280801916157$

Larbi, R., A., Gülgün, B. Pierre and P. Bernard, 2011. Scheduling cross docking operations under full, partial and no information on inbound arrivals. Comput. Operations Res., 38: 889-900.

DOI: 10.1016/j.cor.2010.10.003

Larbi, R., G. Alpan and B. Penz, 2009. Scheduling transshipment operations in a multiple inbound and outbound door crossdock. Proceedings of the International Conference on Computers and Industrial Engineering, Jul. 6-9, IEEE Xplore Press, Troyes, pp: 227-232.

DOI: 10.1109/ICCIE.2009.5223927

Larbi, R., G. Alpana, P. Baptisteb and B. Penza, 2007. Scheduling transshipment operations in a single strip and stack doors crossdock. Proceedings of the 19th International Conference on Production Research, (CPR' 07), pp: 1-6.

Lee, K.K., B. Soo and C.M. Joo, 2012. Genetic algorithms for door-assigning and sequencing of trucks at distribution centers for the improvement of operational performance. Int. J. Expert Syst. Applic., 39: $12975-12983$.

DOI: 10.1016/j.eswa.2012.05.057

Lee, Y.H., J.W. Jung and K.M. Lee, 2006. Vehicle routing scheduling for cross-docking in the supply chain. Comput. Ind. Eng., 51: 247-256. DOI: $10.1016 /$ j.cie.2006.02.006

Li, Y., A. Lim and B. Rodrigues, 2004. CrossdockingJIT scheduling with time windows. J. Operational Res. Society, 55: 1342-1351. DOI: $10.1057 /$ palgrave.jors.2601812

Li, Z., C. Sim, L. Hwee, M.Y. Hean and Y.G. Lim, 2008. Optimal product allocation for crossdocking and warehousing operations in FMCG supply chain. Proceedings of the IEEE International Conference on Service Operations and Logistics and Informatics, Oct. 12-15, IEEE Xplore Press, Beijing, pp: 29632968. DOI: 10.1109/SOLI.2008.4683042

Li, Z.P., M.Y.H. Low, M. Shakeri and Y.G. Lim, 2009. Cross docking planning and scheduling: Problems and algorithms. SIMTech Technical Reports, 10: 159-167.
Liao, T.W., P.J. Egbelu and C. Pei-Chann, 2013. Simultaneous dock assignment and sequencing of inbound trucks under a fixed outbound truck schedule in multi-door cross docking operations. Int. J. Production Econ., 141: 212-229. DOI: $10.1016 /$ j.ijpe.2012.03.037

Ling, L., 2007. Supply Chain Management: Concepts, Techniques and Practices Enhancing the Value Through Collaboration. 1st Edn., World Scientific, Hackensack, NJ, ISBN-10: 9812700722 , pp: 347.

McWilliams, D.L., P.M. Stanfield and C.D. Geiger, 2005. The parcel hub scheduling problem: A simulation-based solution approach. Comput. Industrial Eng., 49: 393-412. DOI: $10.1016 /$ j.cie.2005.07.002

Mentzer, J.T., W. DeWitt, J.S. Keebler, S. Min and N.W. Nix et al., 2011. Defining supply chain management. J. Bus. Logistics, 22: 1-25. DOI: $10.1002 / \mathrm{j} .2158-1592.2001 . t b 00001 . x$

Miao, Z., 2006. Optimization problems in a crossdocking distribution system. Ph.D. Thesis, University of Science and Technology, Hong Kong.

Miao, Z., F. Yang, F. Ke and D. Xu, 2010. Transshipment service through crossdocks with both soft and hard time windows. Annals Operations Res., 192: 21-47. DOI: $10.1007 / \mathrm{s} 10479-010-0780-4$

Napolitano, M., E. Warehousing and J.E. Gross, 2000. Making the Move to Cross Docking: A Practical Guide to Planning, Designing and Implementing a Cross Dock Operation. 1st Edn., WERC, Warehousing Education and Research Council, Oak, ISBN-10: 189266318X, pp: 181.

Pierre, B. and M.Y. Maknoon, 2007. Cross-docking: Scheduling of incoming and outgoing semi trailers. Proceedings of the 19th International Conference on Production Research, (CPR' 07), pp: 1-6.

Rouwenhorst, B., B. Reuter, V. Stockrahm, G.J. Van Houtum and R.J. Mantel et al., 2000. Warehouse design and control: Framework and literature review. Eur. J. Operational Res., 122: 515-533. DOI: $10.1016 / \mathrm{S} 0377-2217(99) 00020-\mathrm{X}$

Sadykov, R., 2012. Scheduling incoming and outgoing trucks at cross docking terminals to minimize the storage cost. Ann. Operations Res., 201: 423-440. DOI: $10.1007 / \mathrm{s} 10479-012-1232-0$

Saharidis, G.K.D., M.M. Golias and T. Zhang, 2012. Discrete time formulation for the assignment problem applied in cross docking facilities. Transportation Research Board of the National Academies

Saxena, R., 2007. Cross-docking demystified.

Shakeri, M., M. Low and L. Zhengping, 2008. A generic model for crossdock truck scheduling and truck-todoor assignment problems. Proceedings of the 6th IEEE International Conference on Industrial Informatics, Jul. 13-16, IEEE Xplore Press, Daejeon, pp: 857-864.

DOI: $10.1109 /$ INDIN.2008.4618221 
Shakeri, M., M.Y.H. Low, S.J. Turner and E.W. Lee, 2012. A robust two-phase heuristic algorithm for the truck scheduling problem in a resource-constrained crossdock. Comput. Operations Res., 39: 25642577. DOI: $10.1016 /$ j.cor.2012.01.002

Shuib, A. and W.N.A.W.A. Fatthi, 2012. A review on quantitative approaches for dock door assignment in cross-docking. Int. J. Adv. Sci. Eng. Inf. Technol., 2: 30-34.

Soltani, R. and J. Sadjadi, 2010. Scheduling trucks in cross-docking systems: A robust meta-heuristics approach. Trans. Res. Part E: Logistics Trans. Rev., 46: 650-666. DOI: 10.1016/j.tre.2009.12.011

Stalk, G., P. Evans and L.E. Sgulman, 1992. Competing on Capabilities: The New Rules of Corporate Strategy. 1st Edn., Harvard Business Review, pp: 11.

Thapa, G.B., T.N. Dhamala and S.R. Pant, 2011. Crossdocking operations for supply chain logistics in JIT production and distribution systems. J. Institute Eng., 8: 219-230. DOI: 10.3126/jie.v8i1-2.5114

Tsui, L.Y. and C.H. Chang, 1992. An optimal solution to a dock door assignment problem. Comput. Industrial Eng., 23: 283-286.

DOI: $10.1016 / 0360-8352(92) 90117-3$
Vahdani, B., R. Soltani and M. Zandieh, 2010. Scheduling the truck holdover recurrent dock crossdock problem using robust meta-heuristics. Int. J. Advanced Manufacturing Technol., 46: 769-783. DOI: $10.1007 / \mathrm{s} 00170-009-2152-2$

Van Belle, J., P. Valckenaers and D. Cattrysse, 2012. Cross-docking: State of the art. Omega, 40: 827846. DOI: 10.1016/j.omega.2012.01.005

Vis, I.F.A. and K.J. Roodbergen, 2008. Positioning of goods in a cross-docking environment. Comput. Ind. Eng., 54: 677-689. DOI: 10.1016/j.cie.2007.10.004

$\mathrm{Wu}$, Y., M. Dong and D. Yang, 2011. Cross-docking centre operation optimization using simulationbased genetic algorithm. J. Eng. Manufacture, 225: $1175-1187$. DOI: $10.1177 / 2041297510393623$

Yang, K.K., J. Balakrishnan and C.H. Cheng, 2010. An analysis of factors affecting cross docking operations. J. Bus. Logistics, 31: 121-148. DOI: $10.1002 / j .2158-1592.2010 . t b 00131 . x$

$\mathrm{Yu}, \mathrm{W}$. and P.J. Egbelu, 2008. Scheduling of inbound and outbound trucks in cross docking systems with temporary storage. Eur. J. Opera. Res., 184: 377-396. DOI: 10.1016/j.ejor.2006.10.047 